\title{
The Science Guiding Selection of an Aerosol Delivery Device
}

\author{
Timothy R Myers MBA RRT-NPS FAARC
}

\author{
Introduction \\ Types of Aerosol Delivery Devices \\ Small-Volume Nebulizers \\ Pneumatically Powered Nebulizers \\ Ultrasonic Nebulizer \\ Mesh Nebulizer \\ Other Nuances and Characteristics of SVNs \\ Pressurized Metered Dose Inhalers and Accessories \\ Conventional pMDI \\ Breath-Actuated and Breath-Controlled pMDI \\ Soft-Mist pMDI \\ Accessory Devices \\ Dry Powder Inhaler \\ Single-Dose DPI \\ Multiple Unit-Dose DPI \\ Multiple-Dose DPI \\ Selecting an Aerosol Delivery Device \\ Conclusions
}

\begin{abstract}
Aerosol therapy continues to be considered as one of the cornerstones of the profession of respiratory care, even after 60 years. Aerosol therapy serves as a critical intervention for both exacerbations and chronic maintenance for a variety of respiratory care conditions. Aerosol therapy uniquely blends both the art and science of medicine together to produce the practical and necessary clinical outcomes for patients with respiratory diseases. This review was presented as part of the New Horizons Symposium on how to guide the scientific selection of an appropriate aerosol device. Key words: aerosol therapy; respiratory care; inhaler; nebulizer. [Respir Care 2013;58(11): 1963-1973. (c) 2013 Daedalus Enterprises]
\end{abstract}

\section{Introduction}

Medications are part of the management regimen and care in hundreds of medical conditions. The use of inhaled

Mr Myers is an Associate Executive Director of the American Associa-
tion for Respiratory Care (AARC).

Mr Myers presented a version of this paper at the 28th New Horizons in Respiratory Care Symposium, "The Scientific Basis for Respiratory Care," at the AARC Congress 2012, held November 10-13, 2012, in New Orleans, Louisiana. aerosols allows selective treatment of the lungs by achieving a high drug concentration in the airway while reducing systemic adverse effects. ${ }^{1}$ Safe and effective medication

\footnotetext{
The author has disclosed no conflicts of interest.

Correspondence: Timothy R Myers MBA RRT-NPS FAARC, American Association for Respiratory Care, 9425 N MacArthur Boulevard, Suite 100, Irving TX 75063. E-mail: myers@aarc.org.
}

DOI: $10.4187 /$ respcare. 02812 
Table 1. Five "Rights" of Medications

The right patient

The right medication

The right time

The right route

The right dose

Table 2. Advantages and Disadvantages of Inhaled Medications
Advantages

Generally smaller than systemic doses

Faster onset of action than oral dosing

Direct delivery

Less frequent and severe systemic effects

Less painful and relatively easy, compared to injections

Disadvantages

Lung deposition is low

Many variables affect efficacy and dose reproducibility

Hand-eye coordination required with pressurized metered-dose inhaler (pMDI)

Lack of knowledge among patients and clinicians

Number and variability of device types

Lack of standardization

(From Reference 2.)

delivery is a major focal area in hospitals and medicine in general today. This increased focus and scrutiny from a medical regulatory standpoint have led to numerous quality initiatives surrounding the 5 "rights" (Table 1) of medication delivery. While these 5 "rights" also apply to aerosolized medications, the delivery of inhaled medications or aerosol therapy is also intricately tied to the delivery devices themselves, which is not always the case with oral or injected medications. Table 2 lists the advantages and disadvantages of inhaled medications.

Aerosols are part of everyday life and play a critical role in the management and treatment of patients with chronic respiratory conditions. Understanding the science of the therapy and its associated technology are vital to successful intervention, treatment, and education for the care and management of chronic respiratory disease.

Methods for generating aerosols, formulating drugs, and administering medications effectively to the desired site of action constitute the science of aerosol drug delivery, ${ }^{2}$ an intricate science in that it is also an art. The art of the therapy involves matching the right aerosol delivery device with the patient's physical and cognitive abilities to promote optimized care.

Effective inhalation of aerosolized medications from a scientific perspective relies on both the mechanism of aerosol deposition and its relationship to aerosol particle size. The size of aerosol particles plays an important function in lung deposition, in addition to the velocity of the particle, and settling time during the inspiratory cycle of breathing.

The primary mechanism of aerosol deposition within the respiratory system involves 3 distinct factors of deposition: inertial impaction, gravitational sedimentation (settling), and diffusion. When aerosolized particles tend to be larger $(>5 \mu \mathrm{m})$ and faster-moving, inertial impaction occurs most commonly in the upper airways or is filtered out in the naso-oropharynx by the narrow passages and high airways resistance. Particles that fall within the $1-5 \mu \mathrm{m}$ size typically deposit based on a function of particle mass and inspiratory time, with the rate of settling proportional to particle size and mass, which is referred to as gravitational settling. The smallest aerosol particles $(<1 \mu \mathrm{m})$ tend to be deposited based on diffusion. Particle size is especially important when dealing with the pediatric population.

Delivery technology for aerosolized medications, regardless of device, produces a mixture of aerosol particle sizes (polydisperse particles). The scientific unit of measure (in $\mu \mathrm{m}$ ) that quantifies a polydisperse aerosol is referred to as the mass median diameter. When the science talks about deposition, it is typically reported as the mass median aerodynamic diameter, or MMAD. The MMAD is the numerical value where particle size evenly divides the mass, or amount of the drug above and below which $50 \%$ of the mass of the particles is contained.

Optimal particle size for most inhaled respiratory medications to achieve deposition in the periphery of the lung falls into the particle size range of $1-5 \mu \mathrm{m}$. As particle size increases above $5 \mu \mathrm{m}$, aerosol deposition shifts from the periphery of the lung to the conducting airways. Oropharyngeal deposition increases as particle size increases above $10 \mu \mathrm{m}$. Exhaled loss is high with very small particles of $1 \mu \mathrm{m}$ or less.

In addition to particle size, the inspiratory flow rate of the patient also plays a synergistic role in the location of the medication deposition. Higher inspiratory flow in the upper airways promotes impaction of particles from the nares to the larynx, particularly for particles of MMAD of 3-5 $\mu \mathrm{m} .^{3}$

When dealing with an infant or a child, these principles also apply, but are also influenced by other variables as well. Studies of a variety of respiratory tract disorders have shown that the major patient related factors that determine and/or limit lower respiratory tract aerosol deposition are lower respiratory tract anatomy and physiopathology, rather than specific diseases. ${ }^{4}$

\section{Types of Aerosol Delivery Devices}

Aerosol delivery devices predominantly reside in one of 3 classifications: small-volume nebulizer (SVN), pressurized metered-dose inhaler (pMDI), and dry powder inhaler 
Table 3. Types of Aerosol Delivery Devices

\begin{tabular}{cc}
\hline \hline $\begin{array}{c}\text { Small-volume } \\
\text { nebulizer } \\
\text { Metered-dose } \\
\text { inhaler }\end{array}$ & $\begin{array}{c}\text { Converts liquid drug solution or suspension into } \\
\text { aerosol particles of varying particle sizes } \\
\text { Dry-powder } \\
\text { inhaler }\end{array}$ \\
$\begin{array}{c}\text { by mall, portable device that dispenses multiple doses } \\
\text { with breath-actuated dosing system based on } \\
\text { inspiratory flow }\end{array}$ \\
\hline
\end{tabular}

(DPI). Table 3 provides a brief description for each of the delivery devices. Each specific device has its own nuances, which leads to a large potential disadvantage for inhaled medications. Inappropriate technique can lead to suboptimal dosing of medications and less than acceptable disease control. In the last few decades (Fig. 1), a proliferation of inhalation devices has resulted in a confusing number of choices for the healthcare provider, and in confusion for both clinicians and patients trying to use these devices correctly. ${ }^{5}$

For several decades, clinicians and patients alike believed that SVNs were more effective than pMDIs, particularly for quick relief mediations during exacerbations of air-flow obstruction. A systematic review of the evidence documented equivalent clinical results, regardless of the device used, for quick relief medications, provided that the patient utilizes the device correctly, despite the SVN providing the higher nominal dose. ${ }^{5}$

As science has continued to refine the technology and devices for aerosol delivery, newer aerosol devices and drug formulations are increasing the efficiency of lung deposition, when compared to the traditional devices commonly used. New devices, such as the Respimat inhaler (Boehringer Ingelheim Pharmaceuticals, Ingelheim, Germany), have shown lung depositions of $40 \% .{ }^{6}$ While the dose of drug delivered to the lung has high variability between devices, aerosol delivery devices with relatively low lung deposition fraction have clinically demonstrated desired therapeutic outcomes in their target audience.

\section{Small-Volume Nebulizers}

SVNs are typically powered from a gas, electrical, or battery powered source and convert drug solutions or suspensions into aerosols that target the patient's lower respiratory tract with minimal patient cooperation. The mechanism of action and design of SVNs has a large variability, and each has its own specific design that requires background and knowledge to utilize the device to its fullest functionality. SVNs are typically designed and classified into one of 3 categories: pneumatic, ultrasonic, or mesh.

\section{Pneumatically Powered Nebulizers}

The main mechanism of action for the pneumatically powered nebulizer is to entrain the solution or suspension to be aerosolized through the generated gas stream, causing a shearing into a liquid film. As this liquid film is highly unstable, it disperses into droplets secondary to surface tension forces. A baffle in the SVN causes the aerosol stream to yield smaller particles. Aerosol particles can be further impacted by environmental factors such as the relative humidity of the carrier gas. Table 4 lists other factors that can impact SVN aerosol output. Nebulizer design changes over the past decade have created different nebulizer categories. ${ }^{7,8}$ Figure 2 pictures the 4 different classes of pneumatically powered nebulizer: jet nebulizer with reservoir tube, jet nebulizer with collection bag or elastomeric reservoir ball, breath-enhanced jet nebulizer, and breath-actuated jet nebulizer.

Jet Nebulizer with a Reservoir Tube. These nebulizers are typically mass produced and are the least expensive and most widely used type of nebulizers in the market today (see Fig. 2A). Jet nebulizers continuously aerosolize, during both inhalation and exhalation, and require a breath-hold to promote optimal deposition. Jet nebulizers, due to their design, emit aerosol to the ambient air during the expiratory phase and any time when the patient is not breathing. ${ }^{8,9}$

Jet Nebulizer With Collection Bag or Elastomeric Reservoir Ball. This class of SVN creates aerosol particles by continuously filling a reservoir (see Fig. 2B). A built-in reservoir with a one-way inspiratory valve allows the patient to inhale medication from the reservoir, and exhales to the atmosphere through an exhalation port between the one-way inspiratory valve and the mouthpiece..$^{8,9}$

Breath-Enhanced Jet Nebulizer. Breath-enhanced nebulizers utilize 2 one-way valves to prevent the loss of aerosol to the environment (see Fig. 2C), while using a reservoir with the inspiratory valve to front-end load medication at the beginning of inspiration. During the expiratory phase, gas passes through an expiratory valve in the mouthpiece to the atmosphere.

Breath-Actuated Jet Nebulizer. Perhaps the most technical and expensive class of SVN nebulizers is the breathactuated nebulizers. The construct of these devices is designed to increase aerosol drug delivery to patients by generating aerosol only during inspiration. Consequently, loss of medication during expiration is greatly reduced (see Fig. 2D). ${ }^{9}$ Breath-actuation triggering mechanisms are categorized as manual, mechanical, and electronic. 


\section{Anticholinergics}

Spiriva
Handihale
(tiotropium
bromide)
Inhalation Powder
Boehringer Ingelheim

Atrovent HFA

(ipratropium bromide HFA)

Inhalation

Aerosol

Boehringer Ingelheim

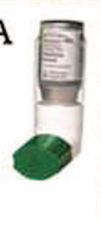

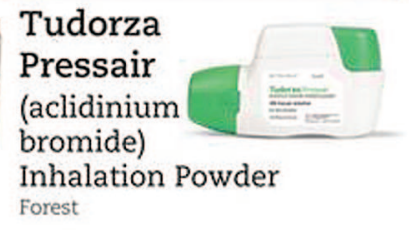

\section{Anticholinergics/ $\beta_{2}$-Agonist Combination}

\section{Combivent \\ Respimat}

(ipratropium bromide and albuterol sulfate) Inhalation Aerosol Boehringer ingelheim

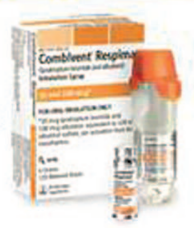

\section{$\beta_{2}$-Agonists}

Foradil Aerolizer

(Formoterol fumarate) Inhalation Powder Novartis
Maxair Autohaler

(pirbuterol acetate) Inhalation Aerosol Graceway

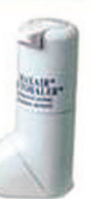

Arcapta Neohaler (indacaterol) Inhalation Powder Novartis

\section{Xopenex HFA} (levalbuterol tartare) Inhalation Aerosol Sepracor

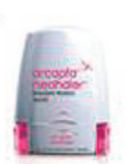

ProAir HFA (albuterol sulfate) Inhalation Aeroso Teva Specialty
Proventil HFA

(albuterol sulfate) Inhalation Aerosol $3 \mathrm{M}$ Pharmaceuticals

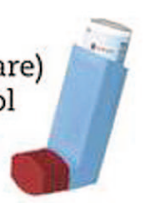

Ventolin HFA

(albuterol sulfate HFA)

Inhalation Aerosol

GlaxoSmithKline

\section{Corticosteroids}

Alvesco

(ciclesonide)

Inhalation

Aerosol

Nycomed

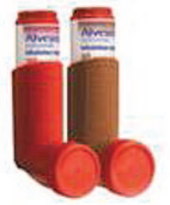

Flovent HFA

(fluticasone propionate) Inhalation Aerosol

GlaxoSmithKline

\section{Asmanex \\ Twisthaler \\ (mometasone) \\ Inhalation \\ Powder \\ Schering}

Pulmicort

Flexhaler

(budesonide)

Inhalation Powder

AstraZeneca LP

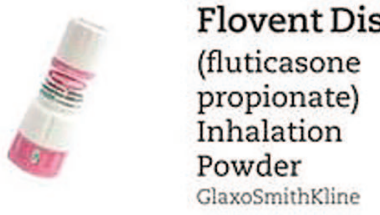

Flovent Diskus

(Iluticasone

Inhalation

GlaxoSmithKline

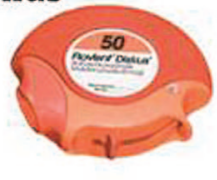

\section{QVAR}

(beclomethasone dipropionate) Inhalation

Aerosol

Teva Specialty Pharmaceuticals

\section{$\beta_{2}$-Agonist/Corticosteroid Combination}

\section{Advair Diskus \\ (fluticasone \\ propionate and salmeterol) \\ Inhalation Powder \\ GlaxoSmithkline}

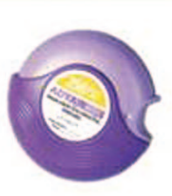

\section{Advair HFA}

(fluticasone propionate and salmeterol xinafoate) Inhalation Aerosol GlaxoSmithKline

\section{Dulera}

(mometasone furoate/ formoterol fumarate dihydrate) Inhalation Aerosol

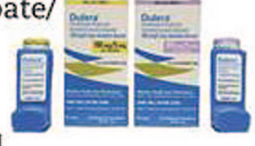
Merck

\section{Symbicort}

(budesonide and formoterol fumarate dihydrate)

Inhalation Aerosol AstraZeneca
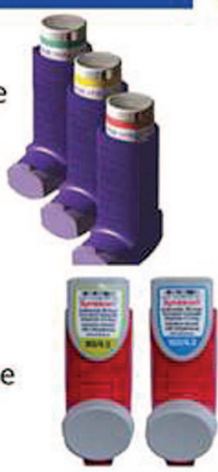

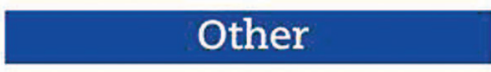

\section{Relenza}

(zanamivir) Inhalation Powder GlaxoSmithKline

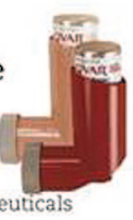

Fig. 1. Common inhalers available in the United States. (From Reference 2.). 
Table 4. Factors That Impact Aerosol Drug Delivery With SmallVolume Nebulizers

Gas flow and pressure

Fill volume and dead volume

Gas density

Humidity and temperature

Breathing pattern

Device interface

(From Reference 2.)

\section{Ultrasonic Nebulizer}

Ultrasonic nebulizers convert electrical energy to highfrequency vibrations using a transducer. These high frequency vibrations are transmitted to the surface of the liquid solution, producing a standing wave that generates aerosol. Small-volume ultrasonic nebulizers are commercially available for delivery of inhalable bronchodilators, but should not be used with suspensions such as budesonide. Ultrasonic nebulizers tend to heat the medication. This raises concerns about disrupting proteins, but that does not affect commonly inhaled medications. ${ }^{10}$

\section{Mesh Nebulizer}

Mesh nebulizers use electricity to vibrate a piezo (at approximately $\sim 128 \mathrm{kHz}$ ) plate or aperture that forces liquid formulations through a fine mesh to generate aerosol. The aerosol particle size can be manipulated to a variety of particle sizes, based on the diameter of the mesh or aperture. Mesh nebulizers are highly efficient and produce minimal residual or dead volume $(0.1-0.5 \mathrm{~mL})$ left over in the device at the end of a treatment. Mesh nebulizers operate on one of 2 basic mechanisms of action: active vibrating mesh, and passive mesh. Active vibrating mesh nebulizers have aperture plates with thousands of funnel-shaped holes vibrated by a piezo-ceramic element that surrounds the aperture plate, while passive mesh nebulizers employ an ultrasonic horn to drive fluid through a mesh screen.

\section{Other Nuances and Characteristics of SVNs}

The design of SVNs and the medications that they aerosolize also add one other unique characteristic: the ability of the pneumatically powered nebulizers to be utilized for continuous aerosol delivery or powered by alternative gas sources (helium-oxygen combinations).

Continuous aerosol drug administration of a bronchodilator is often a consideration in asthma exacerbations. Continuous nebulization therapy is a safe treatment modality, administered with a typical dose range for continuous al- buterol of 5-15 mg/h. ${ }^{11}$ Several configurations have been described for continuous nebulization, including frequent refilling of the nebulizer, use of a nebulizer and infusion pump (Fig. 3), and use of a large-volume nebulizer.

While often an area of clinical controversy, studies have demonstrated that continuous nebulization may be as effective as intermittent aerosol therapy, or may, in fact, be superior to intermittent nebulization in patients with severe pulmonary dysfunction. ${ }^{12,13} \mathrm{~A}$ meta-analysis of results from 6 randomized trials indicated that intermittent administration and continuous administration have similar effects on both lung function and the overall rate of hospitalization, ${ }^{14}$ whereas a Cochrane review of findings from 8 trials suggested that continuous administration resulted in greater improvement in peak expiratory flow and $\mathrm{FEV}_{1}$, and a greater reduction in hospital admissions, particularly among patients with severe asthma. ${ }^{12}$

The second area of aerosol therapy that is unique to SVNs is the use of an alternative gas to power the nebulizer: in this case a combined mixture of helium and oxygen, or, as it is more commonly referred to, heliox. In obstructive airways disease the opportunity to decrease turbulent air flow through obstructive airways with a less dense gas offers the hypothetical advantage of delivering aerosol particles and medications distal to the obstructions. ${ }^{15-18}$ Heliox is a gas mixture of helium $(60-80 \%)$ and oxygen, which is used to improve air flow in patients with partial airway obstruction. ${ }^{19}$

Clinical studies utilizing heliox as the driving gas for delivery of aerosolized asthma medications in asthmatics have reported conflicting results, ${ }^{20}$ which makes evidencebased decisions on its use undeterminable for several possible reasons. As an example, one of the possible reasons for variability in results can be traced to the liter flow used to power the nebulizer. Hess et $\mathrm{al}^{21}$ determined that the flow of heliox with $80 \%$ helium and $20 \%$ oxygen must be increased by about $50 \%$ to generate optimally sized respirable particles.

Nevertheless, new evidence suggests certain benefits in patients with more severe obstruction. In a review, Frazier and Cheifetz summarized the possible uses of heliox in asthma exacerbation (Table 5). ${ }^{22}$ However, since that information is based on between-group comparisons and small studies, the conclusions are not definitive. ${ }^{23}$

Often a question of effective nebulization time becomes a clinical question, and when to discontinue treatment. Two frequently seen practices are for clinicians and patients to tap the SVN to reduce dead volume and increase output, ${ }^{24}$ while the second practice continues nebulization beyond device sputtering, to decrease dead volume. ${ }^{1}$ In fact, research has suggested that after the onset of sputter very little additional drug is inhaled. ${ }^{1,25}$ As patient adherence to therapy is a critical component to out-patient main- 

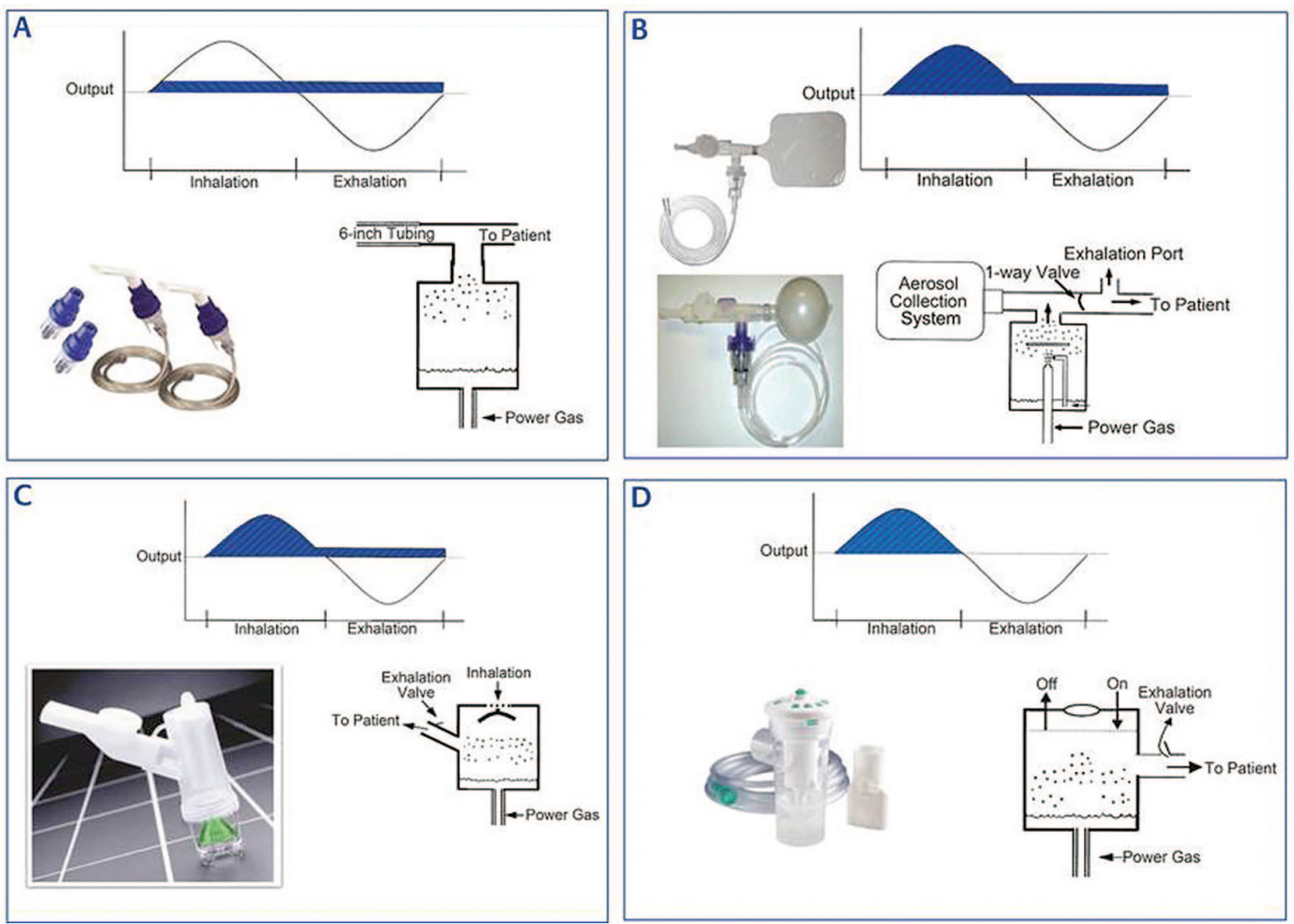

Fig. 2. Types of pneumatic jet nebulizer. The aerosol output is indicated by the shaded areas. A: Pneumatic jet nebulizer with reservoir tube. B: Jet nebulizer with collection bag. C: Breath-enhanced jet nebulizer. D: Breath-actuated jet nebulizer. (From Reference 2.)

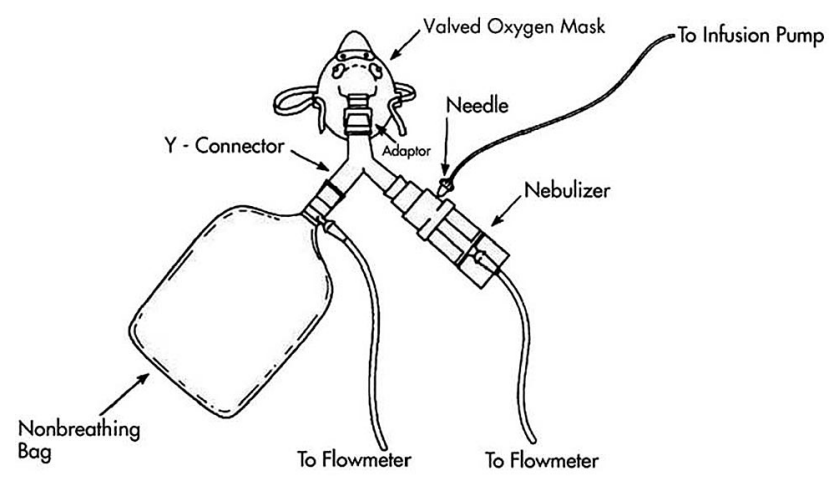

Fig. 3. Setup for continuous aerosol therapy. (From Reference 2.)

tenance therapy, many clinicians recommend discontinuing treatment either at or 1 min after sputter onset.

The final area of clinical concern revolves around the patient-device interface, which occurs mainly in the pediatric and in-patient settings. Mouthpieces and face masks are the 2 interfaces with SVNs, and studies suggest that a mouthpiece interface promotes greater lung deposition than a face mask ${ }^{26,27}$ and is effective in the clinical treatment of
Table 5. Summary of the Clinical Application of Heliox in Asthma Exacerbation

Heliox may benefit initial treatment of pediatric asthma, serving as a bridge until corticosteroids have clinical effect.

Heliox benefits initial treatment of moderate-to-severe asthma exacerbation in the emergency department.

Heliox is most beneficial in the initial treatment period; clinical improvement with heliox, as compared to oxygen-enriched air, becomes less evident over time.

Heliox appears to improve gas exchange in patients with asthma to require intubation, potentially decreasing the ventilator support required.

Heliox allows lower ventilator settings and lower $\mathrm{F}_{\mathrm{IO}_{2}}$, decreasing the risk of ventilator-induced lung injury.

With the increasing use of noninvasive ventilation, heliox might be an adjunct.

$\overline{\text { (From Reference 2.) }}$

children. ${ }^{26,28,29}$ However, using a preferred device can promote adherence, inhaled dose, and desired clinical response. The importance of a closely fitting face mask is a critical 
Table 6. Advantages and Disadvantages of Small-Volume Nebulizers

\author{
Advantages \\ Many drug solutions \\ Can deliver combinations \\ Minimal patient cooperation required \\ Can deliver to all patient ages \\ Concentration and dose can be modified \\ Normal breathing pattern \\ Disadvantages \\ Treatment time variation $(5-25 \mathrm{~min})$ \\ Poor portability \\ Need for power source \\ Risk of drug exposure to eyes \\ Performance variability \\ Assembly and cleaning issues
}

(From Reference 2.)

factor in achieving optimal drug deposition and avoiding nebulizing aerosol into the patient's eyes. Even small leaks of $0.5 \mathrm{~cm}$ around the face mask decrease drug inhaled by children and infants by more than 50\%.30-34

Delivery of aerosolized medications in a blow-by fashion is commonly used for crying babies or uncooperative children, where the nebulization port of a nebulizer is directed toward the patient's face. Studies have documented blow-by medication administration is less efficient, compared with a face mask, as aerosol drug deposition decreases significantly with distance, and this use should be discouraged. ${ }^{30,34-36}$

In summary, while the domain of SVNs can be highly variable, based on the nuances and characteristics described previously, the entire category has some common advantages and disadvantages, which are listed in Table 6.

\section{Pressurized Metered Dose Inhalers and Accessories}

The pMDI has not changed much in the last 50 years. It is a marvel of engineering science, containing a valve that allows a metering of the drug, an actuator boot to trigger the medication and direct it toward the mouth, and medication formulation, which contains a propellant, excipients, and the medication (Fig. 4). ${ }^{37}$

The pMDI is a medical aerosol delivery system that combines a device with a specific formulation and dose of drug. ${ }^{2}$ Actuation of the pMDI delivers a metered dose of medication that must be coordinated with a single inspiration of the patient. Each pMDI canister is required to create reproducible doses $( \pm 20)$ from first to last dose, with a drug shelf life of 12-24 months.

Pressurized MDIs provide a mobile, manually actuated portable device that patients can utilize anywhere at any

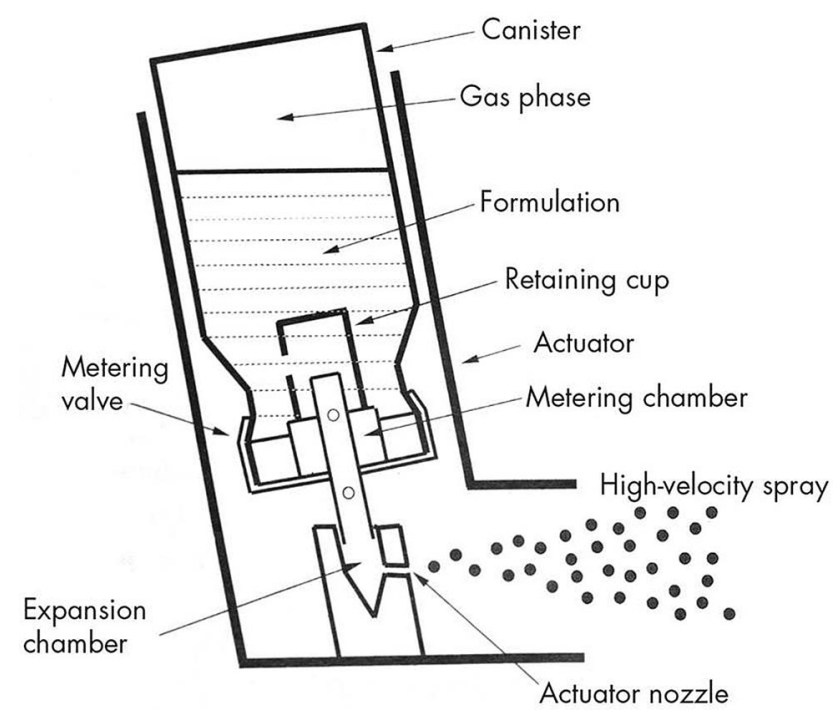

Fig. 4. Standard components of a pressurized metered-dose inhaler. (From Reference 2.)

Table 7. Advantages and Disadvantages of Pressurized MeteredDose Inhalers

\begin{tabular}{l}
\hline \hline Advantages \\
Portable, light, and compact \\
Multiple-dose convenience \\
Short treatment time \\
Reproducible dosing \\
No drug preparation \\
Lower risk of contamination \\
Disadvantages \\
Hand-breath coordination required \\
Active patient required: activation, inhalation pattern, breath-hold \\
Fixed concentration/dose \\
Propellant reaction \\
Aerosol particle impaction in upper airways \\
Most lack dose counting \\
(From Reference 2.)
\end{tabular}

time, and can be used either alone or with an accessory device such as a spacer or valved holding chamber (VHC). There are 3 major types of pMDI: conventional, breathactuated, and soft-mist. Table 7 lists the advantages and disadvantages of pMDIs in general terms.

\section{Conventional pMDI}

The conventional pMDI has a press-and-breathe design. Actuation of the canister into the device boot aligns the hole in the metering valve with the metering chamber and releases the drug-propellant mixture, which then expands and vaporizes to convert the liquid medication into an aerosol. Release of the canister allows the metering valve 
Table 8. Factors Affecting Pressurized Metered-Dose Inhaler Performance and Drug Delivery

Not shaking the pressurized metered-dose inhaler (pMDI) prior to use Storage temperature

Nozzle size and cleanliness

Timing of actuation intervals

Not priming the pMDI per the manufacturer's recommendation

Patient characteristics (eg, age)

Breathing technique

(From Reference 2.)

to refill the chamber with another dose of the drug-propellant mixture. An important component of the pMDI, often overlooked, is the need to prime the metering chamber before use. Although improvements in valve design have reduced the need for priming, it remains prudent to prime the pMDI if it has not been used recently. ${ }^{38,39}$

\section{Breath-Actuated and Breath-Controlled pMDI}

The breath-activated nebulizer is a technology that senses the patient's inspiratory flow and delivers aerosol only when flow triggers the opening of a valve and decreases medication wastage. ${ }^{40}$ Its mechanism is triggered by inhalation through a breath-actuated nozzle, which provides an automatic response to the patient's inspiratory effort. It is important to assess the patient to ensure that they are able to generate a high enough inspiratory flow to activate the triggering mechanism. Breath-actuated pMDIs are not recommended for the younger pediatric patient.

Breath-controlled nebulizers use computer technology to determine a patient's inspiratory flow and volume, and use those to deliver the medication at the beginning of inhalation, allowing the inspired air at the end of inhalation to drive the aerosol deep into the airway. ${ }^{41}$ The theory behind these devices is that less medication is deposited in the oropharyngeal cavity and upper airways, increasing drug availability and deposition in the lung periphery. These devices require a slow inspiratory maneuver, contrasted to breath-actuated or DPIs that require higher inspiratory flow.

\section{Soft-Mist pMDI}

The Respimat (Boehringer Ingelheim Pharmaceuticals, Ingelheim, Germany) is a newly released, propellant-free, soft-mist inhaler that employs mechanical energy from a tensioned spring to generate the soft aerosol plume. When the dose release button is depressed, the energy from the spring forces solution to the mouthpiece, creating a soft aerosol plume that lasts approximately 1.5 seconds. ${ }^{2}$ The soft mist pMDI, similar to a conventional pMDI, requires priming before use and at times when the device has had
Table 9. Advantages and Disadvantages of Pressurized MeteredDose Inhaler Accessory Devices

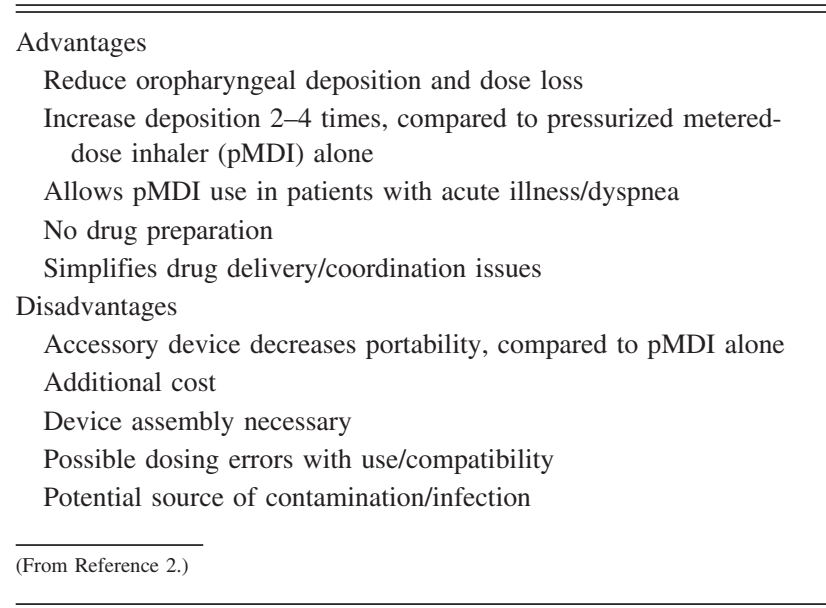

Table 10. Advantages and Disadvantages of Dry Powder Inhalers

\begin{tabular}{l}
\hline \hline Advantages \\
Small and portable \\
Built-in dose counting \\
Propellant-free \\
Breath-actuated \\
Short preparation and delivery time \\
Disadvantages \\
Inspiratory flow dependent \\
Patient dose awareness \\
High oropharyngeal deposition \\
Humidity problems \\
Limited range of drugs \\
Device instructions specific to brand \\
(From Reference 2.) \\
\hline
\end{tabular}

no use. Since the device is propellant-free, there is no need to shake it.

Most pMDIs are manufactured to deliver a targeted drug dose per actuation, of which approximately 10-20\% of the nominal dose per actuation reaches the lung periphery as a fine particle fraction range in which the MMAD is $<5 \mu \mathrm{m}$. Several factors influence the pMDI performance and aerosol drug delivery, and are listed in Table 8.

\section{Accessory Devices}

Spacer devices typically are reservoir-type devices that facilitate delivery of aerosol in patients who are unable to coordinate device actuation and inspiration, by allowing the patient to direct the aerosol into his or her mouth through the reservoir. The mechanism of a spacer device is to provide additional volume to decrease pMDI aerosol velocity, allowing a reduction in particle size. Aerosol 


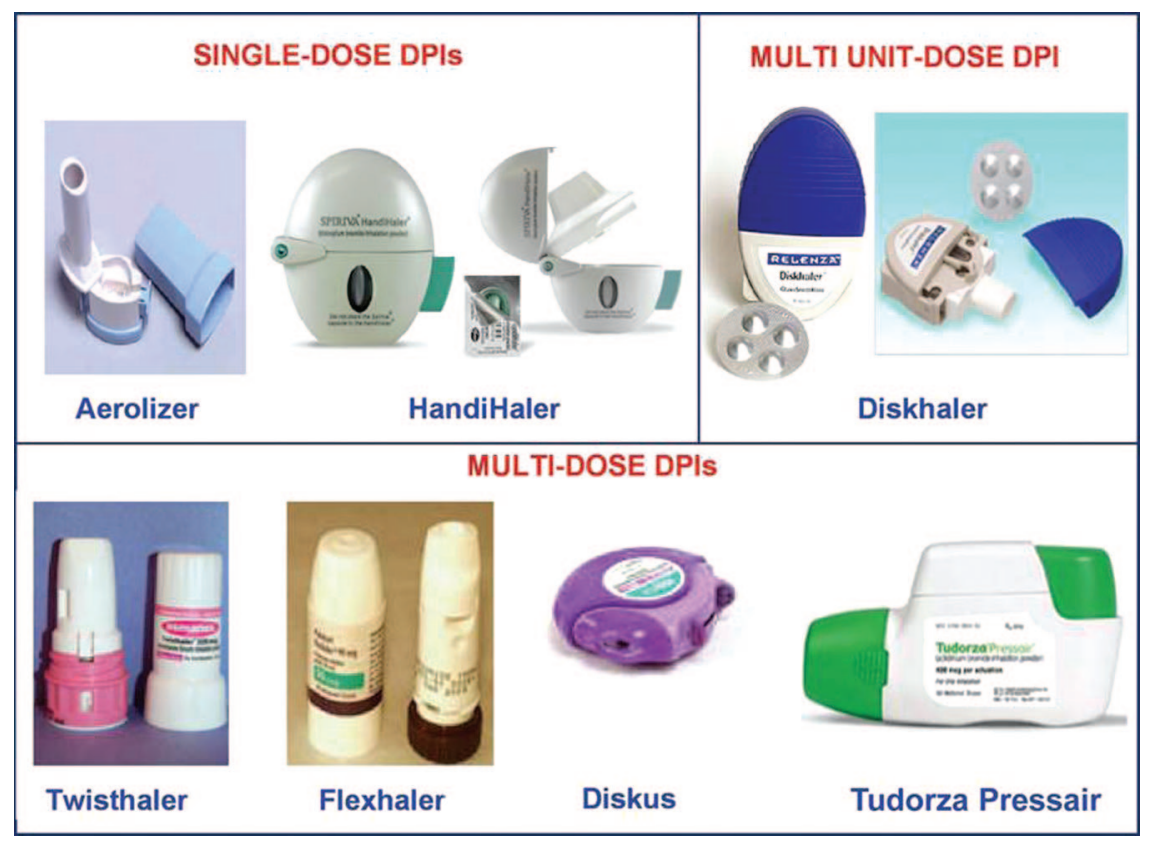

Fig. 5. Dry powder inhalers (DPIs) currently available in the United States, categorized by design features. (From Reference 2.)

retention and discharged dose depend on the size and shape of the spacer, and on the electrostatic charge on the inner walls of plastic spacers. ${ }^{2}$ While actuation-breath coordination is less important with an accessory device, it is still important for the patient to coordinate their inhalation with actuating the inhaler. Table 9 lists the advantages and disadvantages of pMDI accessory devices.

A VHC is a spacer device that incorporates a one-way valve that holds medication within the device until the patient inhales and directs exhalation away from the aerosol in the chamber, reducing aerosol losses resulting from poor hand-breath coordination. For patients unable to use a VHC with a mouthpiece, a low-resistance face mask can be placed on the patient to allow the medication to flow from the chamber into the mask. As with face mask nebulizer therapy, it is important that the mask seals comfortably and completely on the face. Optimal aerosol dosing still depends on inhaling as close to or simultaneously with pMDI actuation into the chamber.

Volume may vary, although in the United States most holding chambers/spacers are $<200 \mathrm{~mL}$. Direction of spray may vary between forward (toward the mouth) and reverse (away from the mouth). Children with low tidal volumes (less than device dead space) may need to take several breaths from a VHC through a face mask for a single pMDI actuation. ${ }^{2}$

An area of clinical concern with pMDI accessory devices is electrostatic charge acquired by the aerosol when generated, or present on the accessory device surface, as it has been demonstrated to decrease aerosol delivery from VHCs. ${ }^{42,43}$ A solution to electrostatic charge was to man- ufacturer VHCs made from conducting materials such as stainless steel or aluminum. ${ }^{44,45}$ Electrostatic free VHCs tend to be more expensive than their counterparts, and there are some practical solutions. Priming a new spacer's walls with 20 doses will coat the inner surface and minimize static charge, ${ }^{45}$ but is probably not cost-effective, as it utilizes up to $10 \%$ of a pMDI's doses. A more practical and real world solution is to wash a nonconducting VHC with dishwashing detergent to reduce surface electrostatic charge, and detergent-washing is now incorporated in most manufacturer instructions..$^{43}$ If this method is utilized, the VHC should not be towel-dried; the VHC should be allowed to air-dry. ${ }^{42}$

\section{Dry Powder Inhaler}

DPIs have become the trendy device over the past decade, and consist of powdered drug formulations that are either in a pure drug form or mixed with an inactive excipient such as lactose. ${ }^{46}$ DPIs are inspiratory flow-driven, do not contain propellant, and are breath-actuated by the patient's inspiratory effort.

Based on the specific device (usually between 30 and $60 \mathrm{~L} / \mathrm{min}$, depending on the device), the patient's inspiratory flow creates energy to deaggregate small drug particles and disperses the particles as aerosol emitted from the device. DPIs do not require coordinated efforts of the patient with the act of inhalation.

There are some unique characteristics of DPIs that make them not applicable to all patient populations. All DPIs, due to the formulary of the drug as a powder, are humidity sensitive. The higher-resistance DPIs may be difficult for 


\section{The Science Guiding Selection of an Aerosol Delivery Device}

young children to use, particularly when they are ill. ${ }^{47}$ If patients exhale into the device, they risk blowing out the medication, and the humidification from exhaled breath can decrease the efficiency of the inhaler, as the particles stick to the orifice. ${ }^{48}$ Table 10 lists the advantages and disadvantages of DPIs.

Currently, DPIs can be organized into 3 categories centered on the dispenser design: single-dose, multiple unitdose, and multiple-dose (Fig. 5). Regardless of the type of DPI, they all have the same essential components incorporated with the inhaler: a drug holder, an air inlet, an agglomeration compartment, and a mouthpiece. ${ }^{2}$

\section{Single-Dose DPI}

Single-dose DPIs have individually wrapped capsules that contain a single-dose of medication and function by dispersing powder medication from a punctured capsule. When using a single-dose DPI, a new drug capsule must be loaded prior to each dose, and the old, used capsule discarded. A potential disadvantage of single-dose DPI is the time and manual dexterity needed to load a dose for each use. Moreover, the capsules should be used only in the intended device and should not be administered in any other device. ${ }^{1}$

\section{Multiple Unit-Dose DPI}

Multiple unit-dose DPIs disperse individual doses that are pre-metered into blisters of medication by the manufacturer. Each blister is mechanically punctured when the cover is lifted, allowing the medication to be inhaled through the mouth without damaging other blister capsules within the device. This design eliminates the potential disadvantages of the single-dose DPI with each capsule, but the patient still needs to periodically load a blister pack into the device.

\section{Multiple-Dose DPI}

Multiple-dose DPI either measures the dose from a powder reservoir or uses blister strips prepared by the manufacturer to deliver repeated doses. ${ }^{2}$ All doses for the prescription (device-drug combination) are self-contained and require no medication loading or manipulation by the patient prior to or after use.

\section{Selecting an Aerosol Delivery Device}

At the end of the day, we are back to where we began: selecting the most appropriate delivery device is very important for optimizing the results of aerosol drug therapy. Evidence indicates that all 3 types of aerosol generators can be equally effective if they are used correctly by the patient. ${ }^{5}$ The criteria to select an aerosol generator can be divided into 4 categories: patient-related, drug-related, device-related, and environmental and clinical factors.
Table 11. Questions to Consider in Matching Patient to Aerosol Delivery Device

In what devices is the desired drug available? Some formulations are available only for a single device, which dictates the device used with that formulation.

What device is the patient likely to be able to use properly, given the patient's age and the clinical setting? Devices that require manual dexterity will be more difficult for elderly patients. Devices that require considerable patient/device coordination may be difficult for the very young or elderly.

For which device and drug combination is reimbursement available? This is an important consideration if the cost is not covered by a third-party payer and the patient cannot afford the out-of-pocket expense.

Which device is least costly? This is an important consideration in the hospital.

Can all the types of inhaled drugs for asthma and COPD that are prescribed for the patient be delivered with the same type of device? Using the same type of device for all the patient's inhaled drugs may facilitate patient teaching and decrease the chance of confusion with multiple devices that require different inhalation techniques, although one study reported that concurrent use of pressurized metered-dose inhaler (pMDI) and dry powder inhaler (DPI) by children with persistent asthma did not adversely affect technique.

Which devices are the most convenient for the patient, family (outpatient use), or medical staff (acute care setting), given the time required for drug administration and device cleaning, and the portability of the device?

How durable is the device?

Does the patient or clinician have any specific device preferences?

(From Reference 2.)

In a Journal Conference review by Hess in RESPIRATORY CARE in $2008,{ }^{1}$ a systematic approach to a series of questions was presented in a step-wise, practical manner, questions that ultimately should be asked by every clinician who is responsible for prescribing or educating patients on respiratory medications and their associated delivery devices. Those patient/device related questions are highlighted in Table 11.

\section{Conclusions}

The science, characteristics, and nuances of each device has been described here, and it is critical that these considerations and factors, along with the specifications of the device, be considered and evaluated with each individual patient. Patient/caregiver evaluation and education are paramount to establish correct device/patient matching, proper administration techniques, and the ultimate efficacy of the drug provided to the patient.

\section{REFERENCES}

1. Hess DR. Aerosol delivery devices in the treatment of asthma. Respir Care 2008;53(6):699-723. 


\section{The Science Guiding Selection of an Aerosol Delivery Device}

2. Gardenhire DS, Hess DR, Myers TR, Rau JL. A guide to aerosol delivery devices for respiratory therapists, 3rd edition. American Association for Respiratory Care; Irving, Texas; 2013.

3. Howarth PH. Why particle size should affect clinical response to inhaled therapy. J Aerosol Med 2001;14(Suppl 1):S27-S34.

4. Amirav I, Newhouse MT. Deposition of small particles in the lung. Paediatr Respir Rev 2012;13(2):73-78.

5. Dolovich MB, Ahrens RC, Hess DR, Anderson P, Dhand R, Rau JL, et al. Device selection and outcomes of aerosol therapy: evidence-based guidelines: American College of Chest Physicians/American College of Asthma, Allergy, and Immunology. Chest 2005;127(1):335-371.

6. Geller DE. New liquid aerosol generation devices: systems that force pressurized liquids through nozzles. Respir Care 2002;47(12):13921404.

7. Dennis JH. A review of issues relating to nebulizer standards. J Aerosol Med 1998;11(Suppl 1):S73-S79.

8. Welch MJ. Nebulization therapy for asthma: a practical guide for the busy pediatrician. Clin Pediatr (Phila) 2008;47(8):744-756.

9. Rau JL, Ari A, Restrepo RD. Performance comparison of nebulizer designs: constant-output, breath-enhanced, and dosimetric. Respir Care 2004;49(2):174-179.

10. Nikander K, Turpeinen M, Wollmer P. The conventional ultrasonic nebulizer proved inefficient in nebulizing a suspension. J Aerosol Med 1999;12(2):47-53.

11. Peters SG. Continuous bronchodilator therapy. Chest 2007;131(1): 286-289.

12. Camargo CA Jr, Spooner CH, Rowe BH. Continuous versus intermittent beta-agonists in the treatment of acute asthma. Cochrane Database Syst Rev 2003;(4):CD001115.

13. Salo D, Tuel M, Lavery RF, Reischel U, Lebowitz J, Moore T. A randomized, clinical trial comparing the efficacy of continuous nebulized albuterol $(15 \mathrm{mg})$ versus continuous nebulized albuterol (15 $\mathrm{mg}$ ) plus ipratropium bromide $(2 \mathrm{mg})$ for the treatment of acute asthma. J Emerg Med 2006;31(4):371-376.

14. Rodrigo GJ, Rodrigo C. First-line therapy for adult patients with acute asthma receiving a multiple-dose protocol of ipratropiumbromide plus albuterol in the emergency department. Am J Respir CritCare Med 2000;161(6):1862-1868.

15. Anderson M, Svartengren M, Bylin G, Philipson K, Camner P. Deposition in asthmatics of particles inhaled in air or in heliumoxygen. Am Rev Respir Dis 1993;147(3):524-528.

16. Svartengren M, Anderson M, Philipson K, Camner P. Human lung deposition of particles suspended in air or in helium/oxygen mixture. Exp Lung Res 1989;15(4):575-585.

17. Darquenne C, Prisk GK. Aerosol deposition in the human respiratory tract breathing air and 80:20 heliox. J Aerosol Med 2004;17(3):278285.

18. Piva JP, Menna Barreto SS, Zelmanovitz F, Amantea S, Cox P. Heliox versus oxygen for nebulized aerosol therapy in children with lower airway obstruction. Pediatr Crit Care Med 2002;3(1):6-10.

19. Hess DR, Fink JB, Venkataraman ST, Kim IK, Myers TR, Tano BD. The history and physics of heliox. Respir Care 2006;51(6):608-612.

20. Kim IK, Saville AL, Sikes KL, Corcoran TE. Heliox-driven albuterol nebulization for asthma exacerbations: an overview. Respir Care 2006;51(6):613-618.

21. Hess DR, Acosta FL, Ritz RH, Kacmarek RM, Camargo CA Jr. The effect of heliox on nebulizer function using a beta-agonist bronchodilator. Chest 1999;115(1):184-189.

22. Frazier MD, Cheifetz IR. The role of heliox in paediatric respiratory disease. Paediatr Respir Rev 2010;11(1):46-53.

23. Rodrigo GJ, Pollack CV, Rodrigo C, Rowe BH. Heliox for nonintubated acute asthma patients. Cochrane Database Syst Rev 2006; (4):CD002884.
24. Everard ML, Evans M, Milner AD. Is tapping jet nebulisers worthwhile? Arch Dis Child 1994;70(6):538-539.

25. Malone RA, Hollie MC, Glynn-Barnhart A, Nelson HS. Optimal duration of nebulized albuterol therapy. Chest 1993;104(4):1114-1118.

26. Nikander K, Agertoft L, Pedersen S. Breath-synchronized nebulization diminishes the impact of patient-device interfaces (face mask or mouthpiece) on the inhaled mass of nebulized budesonide. J Asthma 2000;37(5):451-459.

27. Restrepo RD, Dickson SK, Rau JL, Gardenhire DS. An investigation of nebulized bronchodilator delivery using a pediatric lung model of spontaneous breathing. Respir Care 2006;51(1):56-61.

28. Kishida M, Suzuki I, Kabayama H, Koshibu T, Izawa M, Takeshita $\mathrm{Y}$, et al. Mouthpiece versus facemask for delivery of nebulized salbutamol in exacerbated childhood asthma. J Asthma 2002;39(4): 337-339.

29. Lowenthal D, Kattan M. Facemasks versus mouthpieces for aerosol treatment of asthmatic children. Pediatr Pulmonol 1992;14(3):192-196.

30. Smaldone GC, Berg E, Nikander K. Variation in pediatric aerosol delivery: importance of facemask. J Aerosol Med 2005;18(3):354-363.

31. Amirav I, Newhouse MT. Aerosol therapy with valved holding chambers in young children: importance of the facemask seal. Pediatrics 2001;108(2):389-394.

32. Janssens HM, Tiddens HA. Facemasks and aerosol delivery by metered-dose inhaler valved holding chamber in young children: a tight seal makes the difference. J Aerosol Med 2007;20(Suppl 1):S59-S65.

33. Everard ML, Clark AR, Milner AD. Drug delivery from jet nebulisers. Arch Dis Child 1992;67(5):586-591.

34. Esposito-Festen JE, Ates B, van Vliet FJ, et al. Effect of a facemask leak on aerosol delivery from a pMDI-spacer system. J Aerosol Med 2004;17(1):1-6.

35. Everard ML, Clark AR, Milner AD. Drug delivery from holding chambers with attached facemask. Arch Dis Child 1992;67(5):580-585.

36. Rubin BK. Bye-bye, blow-by Respir Care 2007;52(8):981.

37. Rubin BK. Air and soul: the science and application of aerosol therapy. Respir Care 2010;55(7):911-921.

38. Ross DL, Gabrio BJ. Advances in metered dose inhaler technology with the development of a chlorofluorocarbon-free drug delivery system. J Aerosol Med 1999;12(3):151-160.

39. Leach CL. The CFC to HFA transition and its impact on pulmonary drug development. Respir Care 2005;50(9):1201-1208.

40. Rubin BK. Pediatric aerosol therapy: new devices and new drugs. Respir Care 2011;56(9):1411-1421.

41. Brand P, Friemel I, Meyer T, Schulz H, Heyder J, Haubetainger K. Total deposition of therapeutic particles during spontaneous and controlled inhalations. J Pharm Sci 2000;89(6):724-731.

42. Mitchell JP, Coppolo DP, Nagel MW. Electrostatics and inhaled medications: influence on delivery via pressurized metered-dose inhalers and add-on devices. Respir Care 2007;52(3):283-300.

43. Pierart F, Wildhaber JH, Vrancken I, Devadason SG, Le Souëf PN. Washing plastic spacers in household detergent reduces electrostatic charge and greatly improves delivery. Eur Respir J 1999;13(3):673-678.

44. Bisgaard H, Anhoj J, Klug B, Berg E. A non-electrostatic spacer for aerosol delivery. Arch Dis Child 1995;73(3):226-230.

45. Kenyon CJ, Thorsson L, Borgstrom L, Newman SP. The effects of static charge in spacer devices on glucocorticosteroid aerosol deposition in asthmatic patients. Eur Respir J 1998;11(3):606-610.

46. Newman SP, Busse WW. Evolution of dry powder inhaler design, formulation, and performance. Respir Med 2002;96(5):293-304.

47. Pederson S, Hansen OR, Fuglsang G. Influence of inspiratory flow rate on the effect of a Turbuhaler. Arch Dis Child 1990;65(3):308310 .

48. Meakin BJ, Cainey J, Woodcock PM. Effect of exposure to humidity on terbutaline delivery from turbohaler dry powder inhalation devices. Eur Respir J 1993;6(5):760-761. 